\title{
The Dosimetric Effects of Different Beam Energy on Physical Dose Distributions in IMRT Based on Analysis of Physical Indices
}

\author{
Ismail Eldesoky $^{1}$, Ehab M. Attalla ${ }^{1,2}$, Wael M. Elshemey ${ }^{3}$ \\ ${ }^{1}$ Children's Cancer Hospital, Cairo, Egypt; ${ }^{2}$ National Cancer Institute, Cairo University, Cairo, Egypt; ${ }^{3}$ Department of Biophysics, \\ Faculty of Science, Cairo University, Cairo, Egypt. \\ Email: ismail_eldesoky@yahoo.com
}

Received November $15^{\text {th }}, 2013$; revised December $6^{\text {th }}, 2013$; accepted December $13^{\text {th }}, 2013$

Copyright (C) 2013 Ismail Eldesoky et al. This is an open access article distributed under the Creative Commons Attribution License, which permits unrestricted use, distribution, and reproduction in any medium, provided the original work is properly cited.

\begin{abstract}
This work aimed at evaluating the effect of 6- and 10-MV photon energies on intensity-modulated radiation therapy (IMRT) treatment plan outcome in different selected diagnostic cases. For such purpose, 19 patients, with different types of non CNS solid tumers, were selected. Clinical step-and-shoot IMRT treatment plans were designed for delivery on a Siemens Oncor accelerator with 82 leafs; multi-leaf collimators (MLCs). To ensure that the similarity or difference among the plans is due to energy alone, the same optimization constraints were applied for both energy plans. All the parameters like beam angles, number of beams, were kept constant to achieve the same clinical objectives. The Comparative evaluation was based on dose-volumetric analysis of both energy IMRT plans. Both qualitative and quantitative methods were used. Several physical indices for Planning Target Volume (PTV), the relevant Organs at Risk (OARs) as mean dose (Dmean), maximum dose (Dmax), 95\% dose (D95), integral dose, total number of segments, and the number of MU were applied. Homogeneity index and conformation number were two other evaluation parameters that were considered in this study. Collectively, the use of $6 \mathrm{MV}$ photons was dosimetrically comparable with $10 \mathrm{MV}$ photons in terms of target coverage, homogeneity, conformity, and OAR savings. While 10-MV plans showed a significant reduction in the number of MUs that varied between $4.2 \%$ and $16.6 \%(\mathrm{P}$-value $=0.0001)$ for the different cases compared to 6-MV. The percentage volumes of each patient receiving $2 \mathrm{~Gy}$ and $5 \mathrm{~Gy}$ were compared for the two energies. The general trend was that 6-MV plans had the highest percentage volume, $(\mathrm{P}$-value $=0.0001$, $\mathrm{P}$-value $=0.006$ ) respectively. 10-MV beams actually decreased the integral dose (from average $183.27 \pm 152.38 \mathrm{~Gy}-\mathrm{Kg}$ to $178.08 \pm 147.71 \mathrm{~Gy}-\mathrm{Kg}$, $\mathrm{P}$-value $=0.004)$ compared with 6-MV. In general, comparison of the above parameters showed statistically significant differences between 6-MV and 10-MV groups. Based on the present results, the 10-MV is the optimal energy for IMRT, regardless of the concerns about a potential risk of radiation-induced malignancies. It is recommended that the choice to treat at $10 \mathrm{MV}$ be taken as a risk vs. benefit as the clinical significance remains to be determined on case by case basis.
\end{abstract}

Keywords: 6- and 10-MV Photon Energies; Intensity-Modulated Radiation Therapy (IMRT); Dose-Volumetric Analysis

\section{Introduction}

The goal of radiation therapy is to deliver a lethal amount of dose to target volumes while sparing the surrounding tissues. Intensity-modulated radiation therapy (IMRT) can deliver the conformal dose distributions by varying radiation intensities within each field according to the fluence maps optimized by a treatment planning system (TPS). IMRT is known to improve target coverage and provide better organ-at-risk (OAR) sparing in compari- son with 3D-conformal radiotherapy [1].

For deep-seated tumor treatment, particularly for larger target volumes or larger size patients, using high energy photon is more suitable than low energy photon because of its better penetrating power, skin sparing effect, conformity on PTV, and less normal tissue doses.

Benefits of low energy include the narrow penumbra which results in tighter dose distributions around a target, minimizing irradiation of nearby OARs, negligible neutron contamination, minimizing the head leakage, internal 
scatter. However, there are indications provided by certain investigations that the regions near beam entry receive higher doses and generally a more complex plan containing a greater number of fields, beam segments, and MU are required when low energy is used. This increases treatment delivery times, integral doses. Adverse skin reactions are also a concern for low-energy treatment of deep-seated targets, particularly in large patients [2].

Higher energy tends to increase the risk of induction of secondary malignancies because there are greater leakage, treatment head scatter, patient scatter and particularly photo-neutron contribution [3]. Moreover, high energy beams increasingly diffused beam boundaries due to the long lateral range of secondary electrons [4]. But, there are some indications in a literature of providing better dose coverage to the tumour target, while also improving normal tissue sparing.

However, IMRT is associated with an increase in the number of monitor units (MUs), treatment time, and amount of leakage relative to three-dimensional conformal radiation therapy (3DCRT), which has led to concerns about a potential increased risk of fatal second cancers [5]. It has been reported for 6-MV 3D-CRT and IMRT prostate treatments to vary by $0.6 \%-1.5 \%$ and $1 \%-3.0 \%$, respectively. For $15-\mathrm{MV}$ photons, the risk has been reported to be $3.4 \%$ [6]. Therefore, the choice of optimal energy is an issue of interest and the present study is concerned with introducing an experience with some indications that were chosen to represent common cases seen in the extracranial region.

\section{Materials and Methods}

\subsection{Patient Population}

For this study, we retrospectively selected a cohort of 19 patients affected by different types of non CNS solid tumers cancer. A computed tomography (CT) simulation for each patient was acquired according to departmental protocol and all patient details were anonymised.

All the patients' image sets were chosen such that, there was not much variation in their anatomy. All the patients' Anterior-Posterior (AP) and lateral dimensions were very close. The mean anterior-posterior (AP) separation of these patients was $25.6 \mathrm{~cm}$ and the mean lateral separation was $39.5 \mathrm{~cm}$. The planning target volume varied from 69.65 to $2827.65 \mathrm{cc}$ (Table 1).

\subsection{Treatment Planning}

At our center, 6-MV and 10-MV treatments were delivered on Siemens (Siemens Medical Solutions, Malvern, PA) ONCOR Expression linear accelerator with an 82 multi-leaf collimator (MLC). The clinical IMRT treat-
Table 1. Showed the diagnosis, prescription dose, PTV volume, patient volume for the investigated cases.

\begin{tabular}{cccc}
\hline Site & $\begin{array}{c}\text { Prescribed Dose } \\
\text { (cGy) }\end{array}$ & $\begin{array}{c}\text { PTV Volume } \\
\text { (CC) }\end{array}$ & $\begin{array}{c}\text { Patient Volume } \\
\text { (cc) }\end{array}$ \\
\hline Prostate & 7770 & 185.32 & 15587.72 \\
Prostate & 6000 & 132.21 & 11546.46 \\
Prostate & 7600 & 120.08 & 7133.1 \\
Prostate & 7600 & 86.43 & 9376.82 \\
Prostate & 7600 & 180.67 & 12012.73 \\
Prostate & 7812 & 215.44 & 12878.17 \\
Prostate & 7600 & 619.3 & 12687.04 \\
Prostate & 6000 & 179.17 & 22601.82 \\
Pelvis & 6000 & 141.23 & 10677.87 \\
Abdopelvic Mass & 4500 & 69.65 & 1923.2 \\
Abdomen & 5040 & 682.64 & 4456.22 \\
Abdomen & 2160 & 168.06 & 3591.77 \\
Supra Renal Gland & 2160 & 344 & 4714.47 \\
Paraortic Mass & 5000 & 1350.54 & 12123.49 \\
Paravertebral Mass & 3600 & 303.7 & 7884.06 \\
Lung & 6000 & 572.24 & 11967.63 \\
Lung & 6300 & 382.8 & 16657.31 \\
Mediastinal & 3600 & 643.49 & 7611.67 \\
Anal Canal & 5040 & 2827.65 & 22573.05 \\
\hline
\end{tabular}

ment plans were designed using the KonRad (MRC Systems $\mathrm{GmbH}$, Heidelberg, Germany) inverse planning software release 2.2.23. Dose is calculated using the Multikernel pencil beam algorithm and full three-dimensional ray-tracing with a grid size of $2 \mathrm{~mm}$.

All the patients were treated using 6-MV plans then for study purposes only, and according to hospital research protocol, 10-MV step and shoot IMRT plans were created retrospectively for each patient. To ensure that the similarity or difference between the plans is due to energy alone, the same optimization constraints was applied for each energy planning and all other parameters like beam angles, number of beams, were kept constant. The IMRT plans were created using $7-11$ coplanar and non-opposed fields selected to achieve the plan goals. Fields were selected so that all entrance and exit beams were spaced about the patient [7].

The clinical dose constraints used for these plans were in accordance with Radiation Therapy Oncology Group (RTOG) protocol. The three following objectives should be achieved: 1) target coverage $(95 \%$ of the prescribed dose covered at least $95 \%$ of the PTV while the PTV volume receiving more than $107 \%$ of the prescription dose is limited to zero), 2) OAR sparing to the RTOG limits, 3) sparing of healthy tissue (the CT dataset patient 
volume minus the volume of the largest target) (Stein et al. 1997) [8]. We created additional structures in order to control the dose distribution during optimization. Typically, these optimization-only structures were boolean combinations of targets and normal tissues.

In most of the cases the optimization algorithm could not achieve all the demands at the same time, so only dose volume constraints were modified during the optimization process by either tightening or relaxing the dose-volume histograms (DVHs) to fit the patient-specific differences in the structures of interest. This might cause biased results rather than fair comparisons. Therefore, the OAR dose-volume constraints only were modified unless the PTV coverage and uniformity were changed dramatically. The planning was done by a single physicist and the clinical aspects were reviewed by a single oncologist.

\subsection{Comparative Evaluation}

Dose-volumetric analysis of both energy IMRT plans was performed by both qualitative and quantitative methods. Target coverage was evaluated according to compare maximum and means doses to PTV as well as several physical indices $\left(\mathrm{D}_{98 \%(\mathrm{cGy})}, \mathrm{D}_{95 \%(\mathrm{cGy})}, \mathrm{D}_{5 \%(\mathrm{cGy})}, \mathrm{V}_{95 \%(\%)}\right.$ and $\mathrm{V}_{107 \%(\%)}$ ) were calculated. Where $\mathrm{D}_{\mathrm{n}}$ is the minimum dose delivered by $\mathrm{n} \%$ of the PTV. Homogeneity of dose within PTV has been evaluated by using homogeneity in$\operatorname{dex}(\mathrm{HI})$ as defined by

$$
\mathrm{HI}=\mathrm{D}_{5 \%} / \mathrm{D}_{95 \%}
$$

where $D_{5 \%}$ and $D_{95 \%}$ represent the dose levels on the dose-volume histogram (DVH) curve corresponding to $5 \%$ and $95 \%$ of the target volume, respectively. The values of HI close to unity indicate greater homogeneity.

Conformity of high dose around the target has been evaluated by Conformation number $(\mathrm{CN})$ as described by Van't Riet et al. (1997) because it took into account irradiation of the target volume and irradiation of healthy tissues [9]. This number was defined as follows:

$$
\mathrm{CN}=\mathrm{TV}_{\mathrm{RI}} / \mathrm{TV} * \mathrm{TV}_{\mathrm{RI}} / \mathrm{V}_{\mathrm{RI}}
$$

where $\mathrm{CN}=$ conformation number, $\mathrm{TV}_{\mathrm{RI}}=$ target volume covered by the reference isodose, $\mathrm{TV}=$ target volume, and $\mathrm{V}_{\mathrm{RI}}=$ volume of the reference isodose and according to the ICRU the reference isodose used was isodose $95 \%$.

The dose-volume parameters for organ at risk were analyzed for each plan at 6 and $10 \mathrm{MV}$ by comparing several physical indices. For rectum wall and bladder in prostate cases, Irradiated volumes that received at least $70,66.6,50,40$ and 20 Gy $\left(\mathrm{V}_{70 \mathrm{~Gy}}, \mathrm{~V}_{66.6 \mathrm{~Gy}}, \mathrm{~V}_{50 \mathrm{~Gy}}, \mathrm{~V}_{40 \mathrm{~Gy}}\right.$, $\left.\mathrm{V}_{20 \mathrm{~Gy}}\right)$, also the mean doses $\left(\mathrm{D}_{\text {mean }}\right)$ and $\mathrm{D} 50 \%$ were calculated. Irradiated volumes receiving more than 50, 45, and $30 \mathrm{~Gy}\left(\mathrm{~V}_{50 \mathrm{~Gy}}, \mathrm{~V}_{45 \mathrm{~Gy}}\right.$, and $\left.\mathrm{V}_{30 \mathrm{~Gy}}\right)$ and $\mathrm{D}_{\text {mean }}, \mathrm{D} 50 \%$ to the femoral heads were calculated. While in lung cases, irradiated volumes receiving more than 5, 10, 20, and 30 Gy $\left(\mathrm{V}_{5 \mathrm{~Gy}}, \mathrm{~V}_{10 \mathrm{~Gy}}, \mathrm{~V}_{20 \mathrm{~Gy}}\right.$ and $\left.\mathrm{V}_{30 \mathrm{~Gy}}\right)$ also $\mathrm{D}_{\text {mean }}, \mathrm{D} 1 \%$ and $\mathrm{D} 5 \%$ of the lung were calculated. In the rest of cases the mean doses were calculated for kidney and liver.

In this work, the integral dose (ID) was calculated as the product of the mean dose in Gy for the external contour and the mass of the external contour in $\mathrm{Kg}$ [10]. For simplicity, the mass of the external contour was taken as the product of its volume and a tissue density of $1 \mathrm{~g} / \mathrm{cm}^{3}$.

The integral dose has been defined for $\mathrm{n}$ voxels by

$$
\mathrm{ID}=\sum_{\mathrm{i}}^{\mathrm{n}} \mathrm{D}_{\mathrm{i}} \mathrm{m}_{\mathrm{i}}=\sum_{\mathrm{i}}^{\mathrm{n}} \mathrm{D}_{\mathrm{i}} \mathrm{V}_{\mathrm{i}} \rho_{\mathrm{i}}
$$

where $\mathrm{D}_{\mathrm{i}}, \mathrm{m}_{\mathrm{i}}, \mathrm{V}_{\mathrm{i}}, \rho_{\mathrm{i}}$ are the dose, mass, volume, and density of voxel $\mathrm{i}$.

\section{Statistical Analyses}

Analyses were performed by using a paired t-test to determine dose-volumetric differences for 6-MV vs. 10$\mathrm{MV}$, plans. Differences were considered statistically significant at $\mathrm{p} \leq 0.05$.

\section{Results}

\subsection{Conformity and Homogeneity of the Target}

Figure 1 showed the DVH's for both of the 6-MV and $10-\mathrm{MV}$ treatment plans for some of the investigated cases. The $6 \mathrm{MV}$ plans results were displayed as solid lines and the $10 \mathrm{MV}$ plans results as dashed lines. In most of the cases both energy plans achieved similar PTV coverage. The target coverage parameters at 6 and $10 \mathrm{MV}$ are indicated in (Table 2). Figures 2 and 3 presented the homogeneity index and the dose-volume parameters for the PTV such as $\mathrm{D}_{98 \%}, \mathrm{D}_{95 \%}$ and $\mathrm{D}_{5 \%}$.

A quantitative analysis was carried out to compare the results. There were no clear differences in the homogeneity index among $6 \mathrm{MV}, 10 \mathrm{MV}$ (average $1.104 \pm 0.021$, $1.103 \pm 0.023, p<0.541)$. Most of the dose volume indices for the PTV are slightly better for the 6-MV treatment plans than for the 10-MV plans and it was statistically significant at D5\% $(p<0.026)$. Such a small difference indicates that the low entrance dose from the high-energy beam is, in effect, compensated by the high exit dose. There were no differences on target conformity between the 6-MV treatment plan and the 10-MV plan (average $0.691 \pm 0.088,0.691 \pm 0.087$ for $\mathrm{CN}$ of $6-\mathrm{MV}$ and 10-MV, $p<0.421$ ) (Figure 4).

\subsection{Sparing Organ at Risk}

\subsubsection{Dose to Rectum Wall}

The rectal wall volumes of $6 \mathrm{MV}$ plans that received 40 Gy $\left(\mathrm{V}_{40 \mathrm{~Gy}}\right)$ were larger than those of $10 \mathrm{MV}$ plans (average $50.97 \% \pm 18.09 \%$ vs. $49.85 \% \pm 18.62 \%$ ). The av- 

Analysis of Physical Indices

Dose volume histogram comparison in prostate case

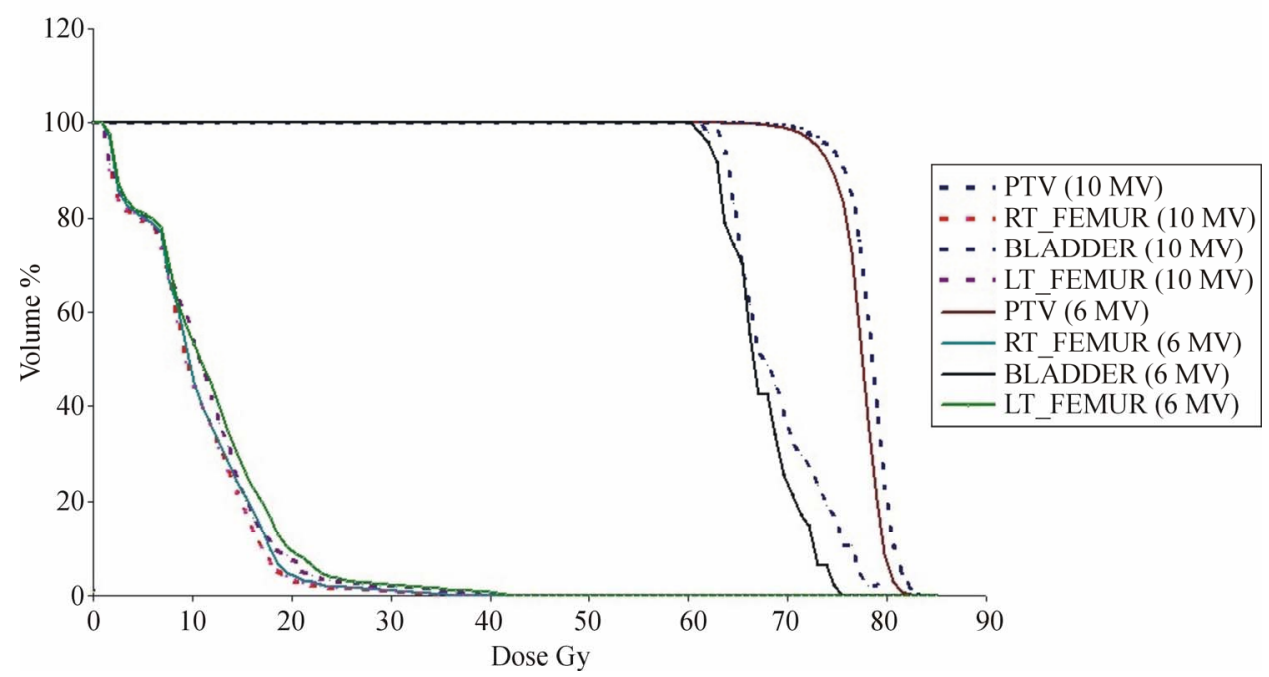

Dose volume histogram comparison in paravertebral case

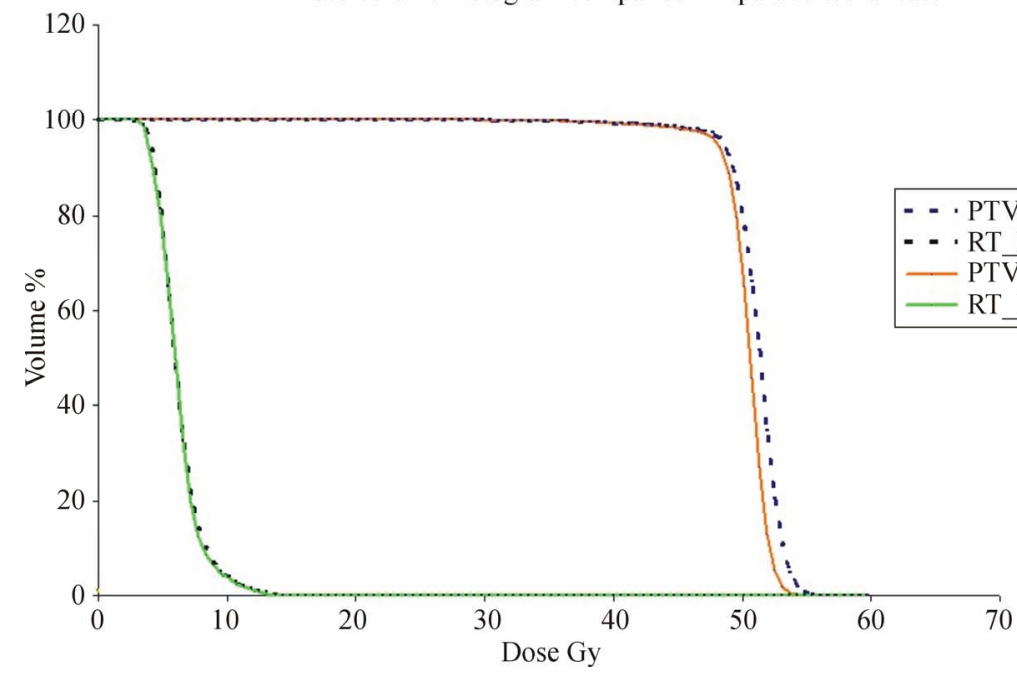

Dose volume histogram comparison in lung case

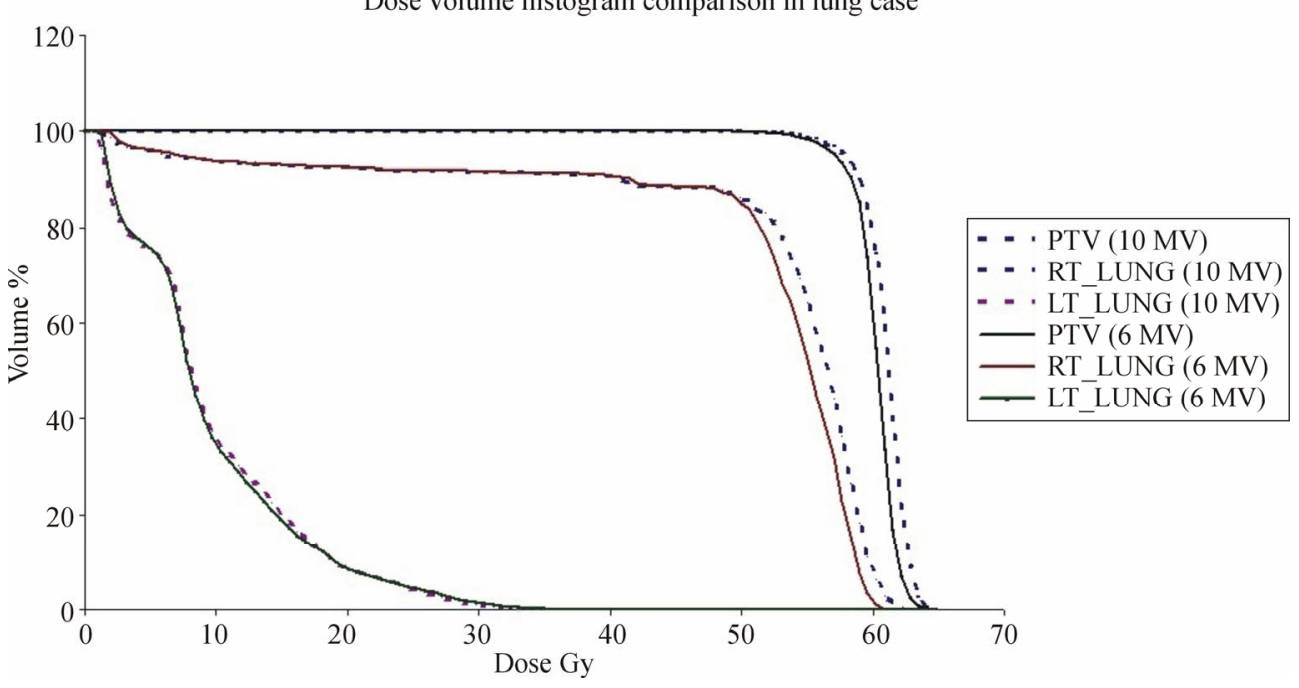

Figure 1. Showed the DVH's for both of the 6-MV and 10-MV treatment plans for some of the investigated cases. 

Analysis of Physical Indices

Table 2. Showed the mean dose, the volume received $95 \%, 107 \%$ of dose (V95\%, V107\%) and maximum dose $D_{\max }$ to the PTVs for the $6 \mathrm{MV}$ and $10 \mathrm{MV}$ plans.

\begin{tabular}{|c|c|c|c|c|c|c|c|c|}
\hline \multirow{2}{*}{ patient number } & \multicolumn{2}{|c|}{ Dmax (cGy) } & \multicolumn{2}{|c|}{ Dmean (cGy) } & \multicolumn{2}{|c|}{ V95\% (\%) } & \multicolumn{2}{|c|}{ V107\% (\%) } \\
\hline & $10 \mathrm{MV}$ & $6 \mathrm{MV}$ & $10 \mathrm{MV}$ & $6 \mathrm{MV}$ & $10 \mathrm{MV}$ & $6 \mathrm{MV}$ & $10 \mathrm{MV}$ & $6 \mathrm{MV}$ \\
\hline 1 & 84.65 & 85.96 & 77.74 & 77.8 & 95 & 95.8 & 0.5 & 0.5 \\
\hline 2 & 66.17 & 66.2 & 60.31 & 60.16 & 95 & 95 & 1.2 & 1.5 \\
\hline 3 & 80.25 & 80.62 & 76.19 & 76.17 & 96.7 & 96.5 & 0 & 0 \\
\hline 4 & 81.76 & 83.6 & 76.59 & 76.78 & 95.5 & 95.8 & 0.2 & 0.6 \\
\hline 5 & 81.19 & 81.36 & 76.11 & 76.4 & 96.1 & 96.4 & 0 & 0.1 \\
\hline 6 & 84.1 & 84.64 & 77.9 & 78.11 & 97 & 97 & 0.2 & 0.2 \\
\hline 7 & 84 & 84.51 & 76.14 & 75.97 & 94 & 93.4 & 1.2 & 1.2 \\
\hline 8 & 67.64 & 65.24 & 59.74 & 59.81 & 95.5 & 94.3 & 0.9 & 0.1 \\
\hline 9 & 62.75 & 63.09 & 59.83 & 59.81 & 98.5 & 98.8 & 0 & 0 \\
\hline 10 & 48.23 & 48.82 & 45.05 & 45.07 & 95.8 & 96.4 & 0.1 & 0.2 \\
\hline 11 & 56.85 & 57.21 & 50.82 & 50.67 & 95.4 & 95.1 & 2.4 & 2.9 \\
\hline 12 & 23.66 & 23.41 & 21.97 & 22 & 98.2 & 98.2 & 1.8 & 1.5 \\
\hline 13 & 23.98 & 24.28 & 21.76 & 21.73 & 94.6 & 94.9 & 1.8 & 1.5 \\
\hline 14 & 56.89 & 57.47 & 50.84 & 50.8 & 97.9 & 97.6 & 3 & 1 \\
\hline 15 & 40.57 & 40.98 & 36.57 & 36.54 & 94.6 & 94.6 & 3.3 & 3.2 \\
\hline 16 & 64.77 & 65.6 & 60.63 & 60.64 & 97 & 97 & 0.6 & 0.6 \\
\hline 17 & 66.93 & 67.83 & 62.71 & 63.11 & 97.9 & 98.2 & 0 & 0.1 \\
\hline 18 & 41.8 & 40.7 & 36.6 & 36.6 & 94.6 & 95.2 & 4.0 & 4.0 \\
\hline 19 & 59.2 & 59.8 & 51.0 & 51.0 & 95.5 & 96.1 & 3.5 & 4.0 \\
\hline Mean & 61.86 & 62.18 & 56.76 & 56.80 & 96.04 & 96.12 & 1.30 & 1.22 \\
\hline SD & 19.28 & 19.56 & 18.22 & 18.27 & 1.37 & 1.45 & 1.35 & 1.35 \\
\hline P-Value & \multicolumn{2}{|c|}{0.141} & \multicolumn{2}{|c|}{0.309} & \multicolumn{2}{|c|}{0.479} & \multicolumn{2}{|c|}{0.541} \\
\hline
\end{tabular}

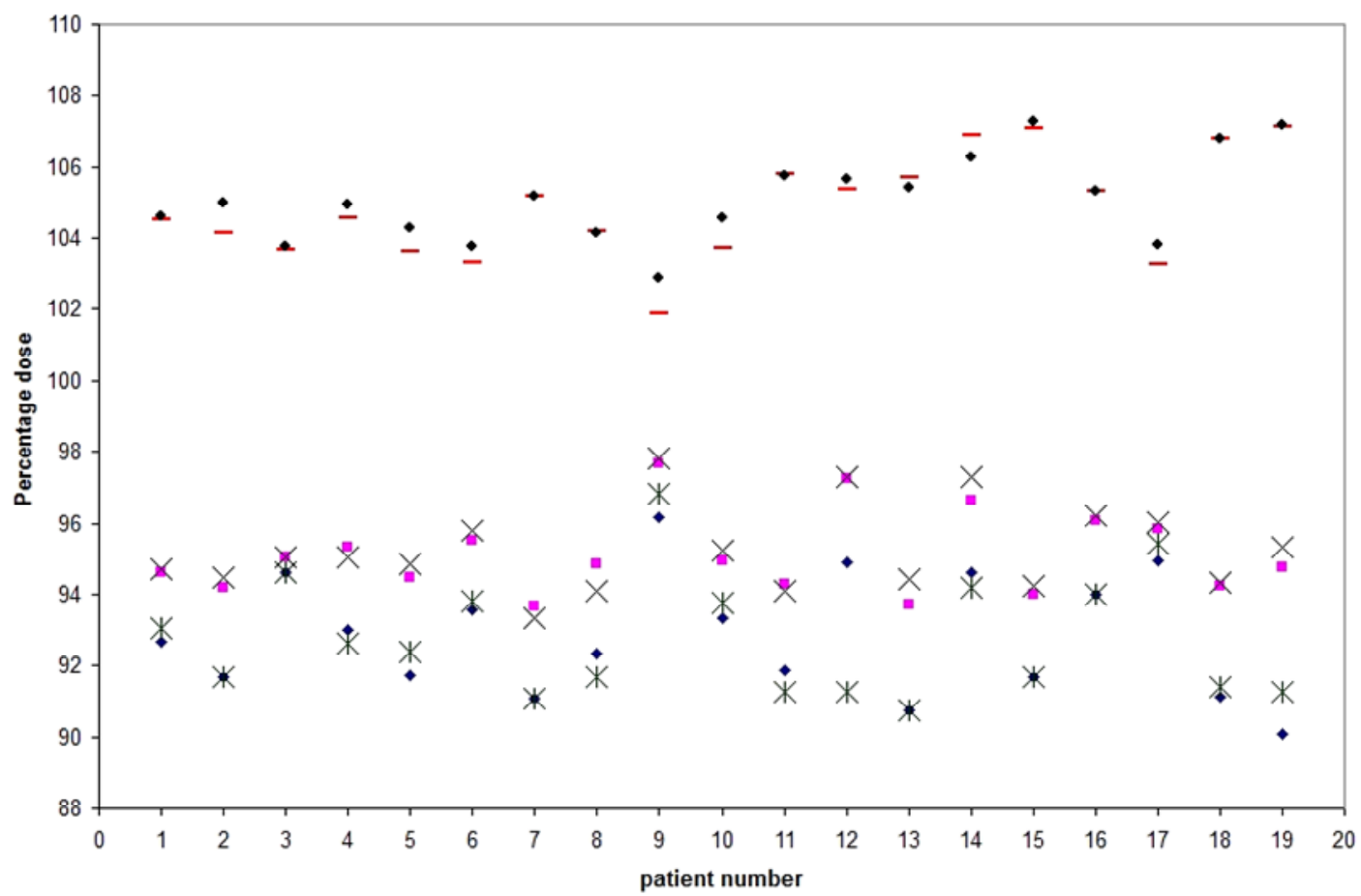

Figure 2. Percentage dose of prescription dose received by each patient. 


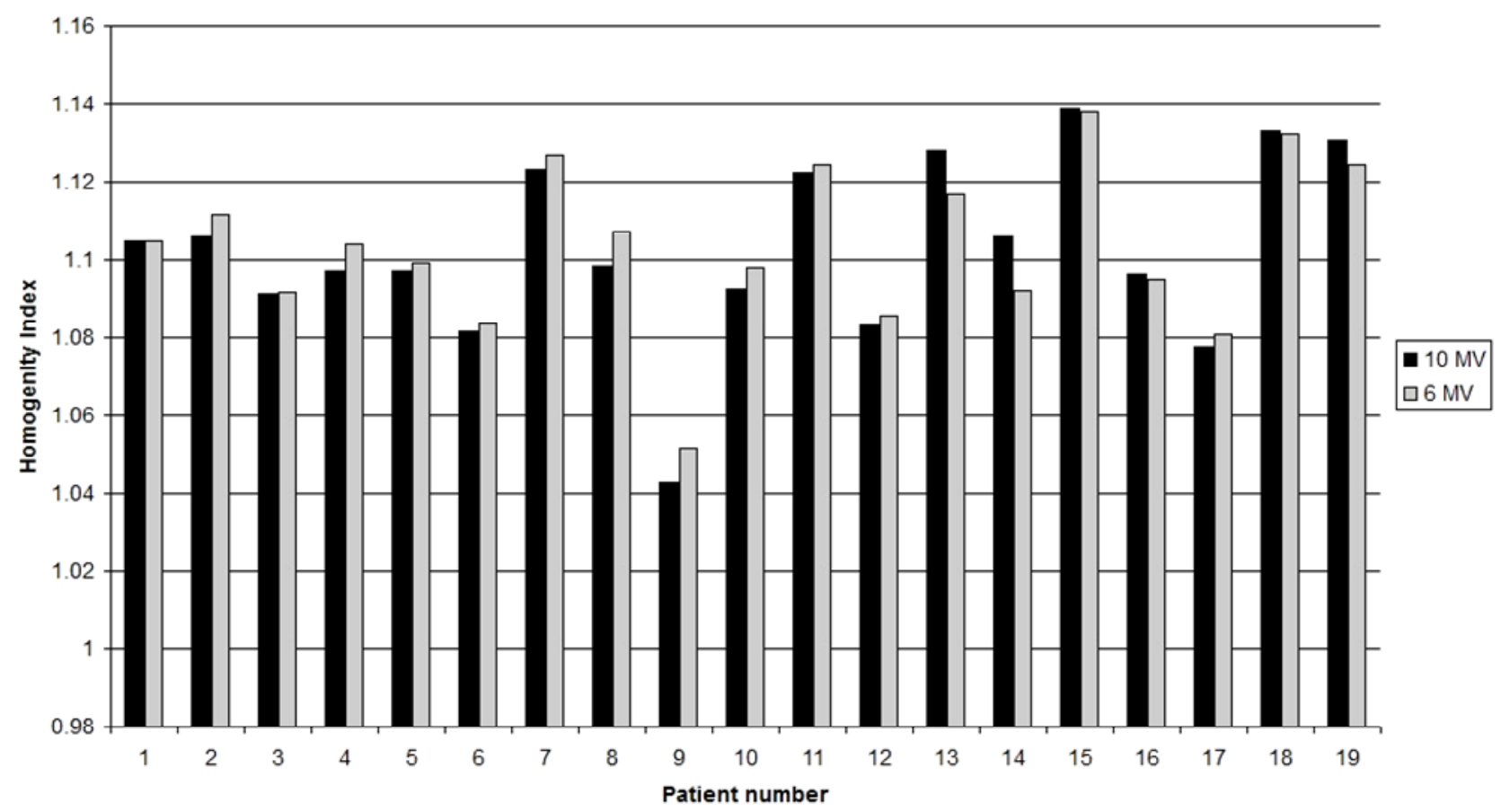

Figure 3. A comparison of homogeneity index between $10 \mathrm{MV}$ and $6 \mathrm{MV}$ plans for the 19 patients.

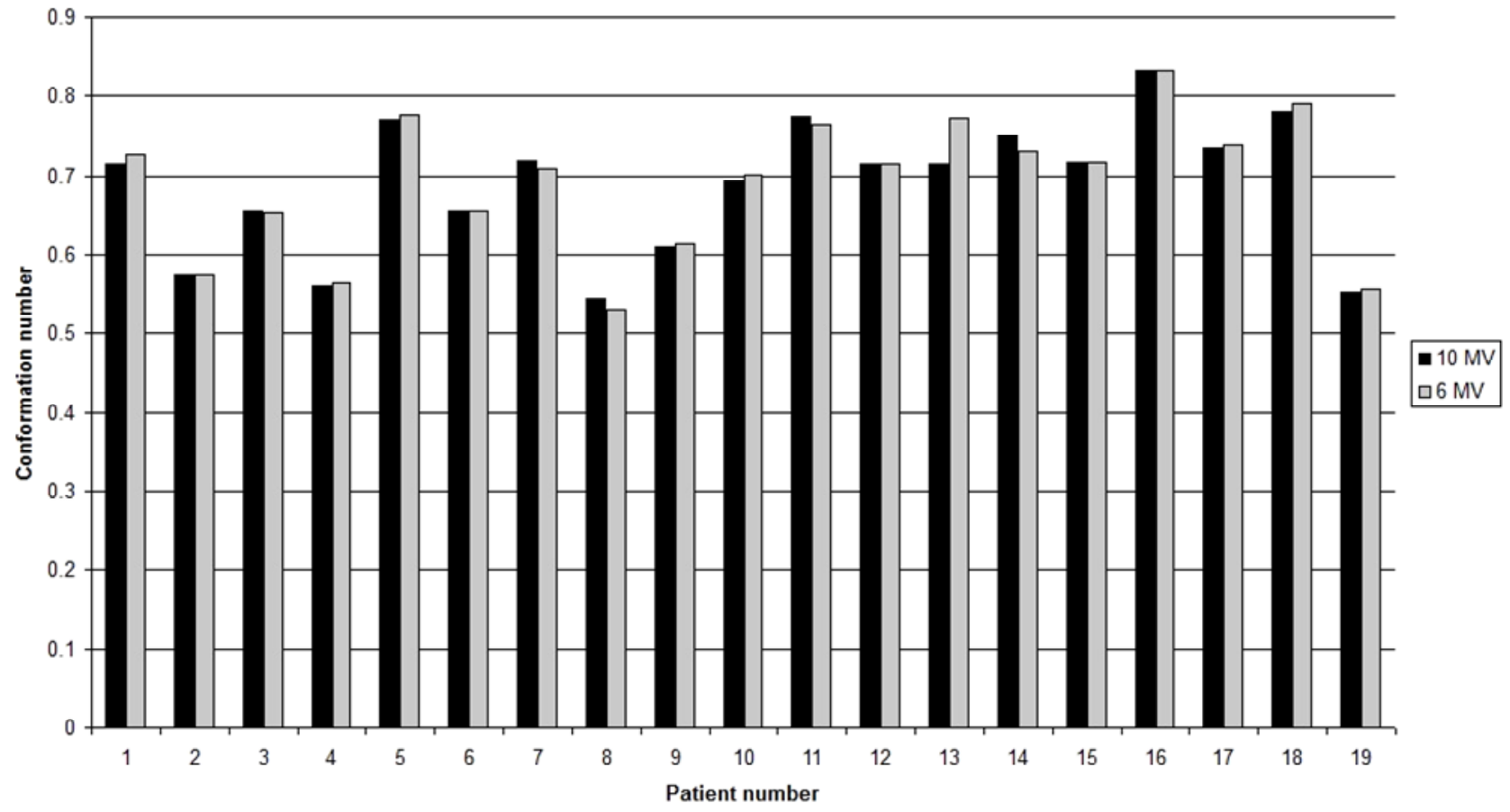

Figure 4. Conformity for both $10 \mathrm{MV}$ and $6 \mathrm{MV}$ plans for the 19 patients.

erage values of the mean dose, $\mathrm{V}_{20 \mathrm{~Gy}}, \mathrm{~V}_{50 \mathrm{~Gy}}$ and $\mathrm{D}_{50 \%}$ of $10 \mathrm{MV}$ plans were smaller than those of $6 \mathrm{MV}$ plans, while the volumes covered by 66.6 and 70 Gy isodose were on average smaller for 6-MV compared with 10$\mathrm{MV}$. The statistical significances of differences in all this dose volume parameters were not reached except for
$\mathrm{D}_{50 \%}$ and $\mathrm{V}_{40 \text { Gy }}(\mathrm{p}<0.02, \mathrm{p}<0.01$ respectively) (Table 3).

\subsubsection{Dose to Bladder}

For bladder, the volumes receiving $\geq 66.6,50,40,20 \mathrm{~Gy}$ and the mean, $\mathrm{D}_{50 \%}$ were smaller with $10-\mathrm{MV}$ than $6-\mathrm{MV}$. 
Table 3. Shows the dose-volume parameters for the different OAR according to the different cases at both energies.

\begin{tabular}{|c|c|c|c|c|}
\hline OAR & DVH parameter & $10 \mathrm{MV}$ & $6 \mathrm{MV}$ & $P$ value \\
\hline \multirow{7}{*}{ Rectum } & mean & $37.79 \pm 8.97$ & $38.01 \pm 18.79$ & 0.21 \\
\hline & V20Gy (\%) & $82.08 \pm 20.02$ & $82.63 \pm 19.77$ & 0.49 \\
\hline & V40Gy (\%) & $49.85 \pm 18.62$ & $50.97 \pm 18.09$ & 0.01 \\
\hline & V50Gy (\%) & $27.39 \pm 14.4$ & $27.59 \pm 14.91$ & 0.82 \\
\hline & V66.6Gy (\%) & $7.52 \pm 8.59$ & $7.46 \pm 8.45$ & 0.51 \\
\hline & V70Gy (\%) & $5.21 \pm 6.04$ & $5.19 \pm 5.98$ & 0.87 \\
\hline & D50\% (Gy) & $35.33 \pm 13.11$ & $36 \pm 13.13$ & 0.02 \\
\hline \multirow{7}{*}{ Bladder } & mean & $40.4 \pm 6.19$ & $40.86 \pm 6.27$ & 0.004 \\
\hline & V20Gy (\%) & $86.74 \pm 13.34$ & $86.99 \pm 13.23$ & 0.1 \\
\hline & V40Gy (\%) & $50.68 \pm 11.91$ & $51.78 \pm 12.28$ & 0.006 \\
\hline & V50Gy (\%) & $30.22 \pm 14.23$ & $30.44 \pm 14.75$ & 0.61 \\
\hline & V66.6Gy (\%) & $11.91 \pm 11.96$ & $12 \pm 12.24$ & 0.74 \\
\hline & V70Gy (\%) & $9.66 \pm 10.22$ & $9.55 \pm 10.25$ & 0.62 \\
\hline & D50\% (Gy) & $39.67 \pm 6.44$ & $40.17 \pm 7.03$ & 0.09 \\
\hline \multirow{5}{*}{ LT head of femur } & mean & $13.33 \pm 6.35$ & $13.55 \pm 6.34$ & 0.11 \\
\hline & V30Gy (\%) & $5.77 \pm 13.7$ & $6.04 \pm 14.19$ & 0.22 \\
\hline & V45Gy (\%) & $0.76 \pm 2.47$ & $0.75 \pm 2.37$ & 0.55 \\
\hline & V50Gy (\%) & $0.38 \pm 1.27$ & $0.33 \pm 1.09$ & 0.34 \\
\hline & D5\% (Gy) & $24.05 \pm 9.55$ & $24.74 \pm 9.53$ & 0.03 \\
\hline \multirow{5}{*}{ RT head of femur } & mean & $13.18 \pm 6.49$ & $13.3 \pm 6.38$ & 0.5 \\
\hline & V30Gy (\%) & $5.72 \pm 14.32$ & $5.9 \pm 13.61$ & 0.45 \\
\hline & V45Gy (\%) & $0.77 \pm 2.18$ & $0.63 \pm 1.7$ & 0.34 \\
\hline & V50Gy (\%) & $0.35 \pm 1.18$ & $0.3 \pm 0.99$ & 0.34 \\
\hline & D5\% (Gy) & $23.7 \pm 9.99$ & $24.45 \pm 9.42$ & 0.49 \\
\hline \multirow{7}{*}{ RT lung } & mean & $15.08 \pm 11.05$ & $15.28 \pm 11.04$ & 0.224 \\
\hline & V5Gy (\%) & $65.47 \pm 32.04$ & $65.97 \pm 31.81$ & 0.199 \\
\hline & V10Gy (\%) & $47.3 \pm 35.83$ & $47.73 \pm 35.42$ & 0.21 \\
\hline & V20Gy (\%) & $27.17 \pm 27.25$ & $27.47 \pm 27.57$ & 0.48 \\
\hline & V30Gy (\%) & $18.07 \pm 21.17$ & $18.27 \pm 21.29$ & 0.18 \\
\hline & D1\% (Gy) & $38.83 \pm 23.41$ & $38.9 \pm 22.81$ & 0.87 \\
\hline & D5\% (Gy) & $35.63 \pm 25.68$ & $35.73 \pm 25.42$ & 0.61 \\
\hline \multirow{7}{*}{ LT lung } & mean & $17.29 \pm 9.24$ & $17.55 \pm 9.53$ & 0.26 \\
\hline & V5Gy (\%) & $81.33 \pm 5.15$ & $82 \pm 5.2$ & 0.37 \\
\hline & V10Gy (\%) & $57.7 \pm 20.19$ & $57.8 \pm 20.25$ & 0.42 \\
\hline & V20Gy (\%) & $31 \pm 24.13$ & $31.67 \pm 25.01$ & 0.33 \\
\hline & V30Gy (\%) & $19.33 \pm 22.42$ & $19.73 \pm 22.51$ & 0.18 \\
\hline & D1\% (Gy) & $44.3 \pm 17.62$ & $44.43 \pm 17.39$ & 0.55 \\
\hline & D5\% (Gy) & $40.2 \pm 18.75$ & $40.47 \pm 18.79$ & 0.02 \\
\hline RT kidney & Mean (Gy) & $9.51 \pm 4.6$ & $9.65 \pm 4.65$ & 0.05 \\
\hline LT kidney & Mean (Gy) & $8.6 \pm 3.52$ & $8.8 \pm 3.49$ & 0.003 \\
\hline Liver & Mean (Gy) & $6.06 \pm 2.2$ & $6.13 \pm 2.18$ & 0.23 \\
\hline
\end{tabular}

While the average value of $\mathrm{V}_{70 \text { Gy }}$ of $6 \mathrm{MV}$ plans was lower than that of $10 \mathrm{MV}$ plans. The differences were statistically significant for $\mathrm{V}_{40 \mathrm{~Gy}}, \mathrm{D}_{50 \%}$ and the mean $(p<$ $0.006, p<0.09, p<0.004$ respectively). 


\subsubsection{Dose to Femoral Heads}

Although the mean, $\mathrm{V}_{30 \text { Gy }}$ and $\mathrm{D}_{5 \%}$ doses of $6 \mathrm{MV}$ plans were higher than those of $10 \mathrm{MV}$ but no significant differences of dose-volume parameters were found between 6-MV and 10-MV energies except for $\mathrm{D}_{5 \%}$ dose in LT femoral head $(p<0.03)$.

\subsubsection{Dose to Lung, Kidney and Liver}

10-MV plans achieved better sparing of both lungs in different dose volume parameters but the results were not statistically significant except for $\mathrm{D}_{5 \%}$ for the left lung ( $p$ $<0.02$ ). Also the DVH's for both kidneys and liver showed the same behavior as lung, both $6 \mathrm{MV}$ and 10 MV plans were able to provide the mean doses of both kidneys and liver below the tolerances, the average mean doses were reduced from $9.65 \pm 4.65,8.8 \pm 3.49$ and 6.13 \pm 2.18 to $9.51 \pm 4.6,8.6 \pm 3.52$ and $6.06 \pm 2.2$ with Pvalues $(\mathrm{p}<0.05, \mathrm{p}<0.003, \mathrm{p}<0.23)$ for right kidney, left kidney and liver respectively.

\subsubsection{Integral Dose and Dose to Normal Tissue}

The dose to different body volumes $\mathrm{D}_{1 \%}, \mathrm{D}_{2 \%}$ and $\mathrm{D}_{5 \%}$ was found to receive slightly higher dose with 6-MV beam than with $10-\mathrm{MV}$ beam. For $\mathrm{D}_{5 \%}$ the change was statistically significant $(p<0.03)$. Evaluation of the ID on normal tissue showed that using 10-MV beams actually decreased the ID (average $183.27 \pm 152.38 \mathrm{~Gy}-\mathrm{Kg}$ to $178.08 \pm 147.71 \mathrm{~Gy}-\mathrm{Kg}, p<0.004)$ compared with 6MV (Table 4).

The percentage volumes of each patient receiving 2 Gy $\left(\mathrm{V}_{2 \text { Gy }}\right)$ and 5 Gy $\left(\mathrm{V}_{5 \text { Gy }}\right)$ were compared. The general trend was that $6 \mathrm{MV}$ plans had the highest volume receiving in excess of 2 and $5 \mathrm{~Gy}$, and $10 \mathrm{MV}$ plans showed the lowest $(84.78 \% \pm 8.96 \%$ vs. $82.97 \% \pm 8.85 \%$ for $\mathrm{V}_{2 \mathrm{~Gy}}$ and $64.57 \% \pm 12.29 \%$ vs. $63.92 \% \pm 12.24 \%$ for $\mathrm{V}_{5 \mathrm{~Gy}}, p<0.0001$ and $p<0.006$, respectively).

Figure 5 showed the results of the beam segmentation optimization. The $6 \mathrm{MV}$ plans showed a reduction in the number of segments (average $79.58 \pm 23.22$ vs. $81.21 \pm$ 23.47) and the reduction was statistically significant ( $p<$ 0.016). The average number of MUs delivered per prescribed Gy of photon for both energies was lower for the 10-MV plans at $269.48 \mathrm{MU} \cdot \mathrm{Gy}^{-1}$ than for the 6-MV plans at $300.76 \mathrm{MU} \cdot \mathrm{Gy}^{-1}$ where the $6-\mathrm{MV}$ plans deliver $10.4 \%$ more monitor units than do the $10-\mathrm{MV}$ plans.

\section{Discussion}

In general, comparison of all above parameters showed that there was little difference between 6-MV and 10MV groups. In practice, to achieve same results of target coverage, conformity, and homogeneity, much tighter constraints are needed in low-energy treatment plans.

For bladder and rectum wall the general trend for 6
MV plans is to save more volume in high-dose regions than $10 \mathrm{MV}$, while $10 \mathrm{MV}$ plans saved more rectum wall in low-dose regions than $6 \mathrm{MV}$, and in both cases the results were clinically acceptable. That can be explained by the fact that low-energy plans can develop tighter dose distributions around a target, while high-energy plans have better penetrating power [11].

For both lungs 10-MV plans was always superior on 6 MV plans but both were clinically equivalent, because lung is a relatively large organ, so while it exhibits a higher partial volume effect but a small increase in dose is unlikely to increase its complication probability significantly [12]. In most of cases the femoral heads receive small doses because it is usually at a clinically insignificant distance from the target.

Due to the penetrating power, the irradiated volume of low dose and the integral dose increased in $6 \mathrm{MV}$ plans. This low-dose volume may not cause acute or subacute clinical morbidity but could potentially be carcinogenic [13]. Statistically the results presented significant differences between 6-MV and 10-MV for both parameters in addition to number of segments and MU's.

Sundaram Thangavelu et al. [14] states that, the slight advantages of 15-MV beam in providing benefits of better normal-tissue sparing and better coverage cannot be considered to outweigh its well-known risk of non-negligible neutron production. Sun and Ma [15] investigated the feasibility of using 6-MV intensity-modulated photons for treating exceptionally large patients with prostate cancer. The study shows that 6-MV is an effective option for treating even very large patients with prostate cancer. Welsh et al. [16] discussed the theoretical grounds for the use of high and low -energy photons as a comparison between disadvantages and advantages but the lake of real data resulted in debate about the conclusion. Boer et al. [17] suggested that the use of an 18 MV IMRT can achieve better target coverage and normal tissue sparing but this benefit can not outweigh the risks of potential secondary malignancies. Also lower energy (6 MV) photon beams was preferred over higher energies (15 - 18 $\mathrm{MV}$ ) in treatment of tumors that abut lung tissue, Wang L et al. [18]. Gopi solaiappan et al. [19] studied the effect of beam energy on the quality of IMRT plans, all the DVH parameters were analyzed in details. The study recommended the use of $6 \mathrm{MV}$ photons for IMRT of prostate cancer.

Almost all the previous research showed that using low-energy photon beams in IMRT was preferred over higher energies. But in case of $10 \mathrm{MV}$ the situation was different since $10 \mathrm{MV}$ photons lie on the threshold energy border for the induction of fatal secondary cancer. Kry et al. estimated negligible neutron contribution at 10-MV Moreover, a study of Hussein et al. [20] which 
The Dosimetric Effects of Different Beam Energy on Physical Dose Distributions in IMRT Based on Analysis of Physical Indices

Table 4. Showed a comparison of the integral dose and low dose distribution in healthy tissue.

\begin{tabular}{|c|c|c|c|c|c|c|c|c|c|c|c|c|}
\hline \multirow{3}{*}{ Patient no. } & \multicolumn{12}{|c|}{ Comparisons of the Integral dose and Low dose distribution in healthy tissue } \\
\hline & \multicolumn{2}{|c|}{ Integral Dose } & \multicolumn{2}{|c|}{$\mathrm{D} 1 \%(\mathrm{~Gy})$} & \multicolumn{2}{|c|}{$\mathrm{D} 2 \%(\mathrm{~Gy})$} & \multicolumn{2}{|c|}{ D5\% (Gy) } & \multicolumn{2}{|c|}{ V2Gy $(\%)$} & \multicolumn{2}{|c|}{ V5Gy (\%) } \\
\hline & $10 \mathrm{MV}$ & $6 \mathrm{MV}$ & $10 \mathrm{MV}$ & $6 \mathrm{MV}$ & $10 \mathrm{MV}$ & $6 \mathrm{MV}$ & $10 \mathrm{MV}$ & $6 \mathrm{MV}$ & $10 \mathrm{MV}$ & $6 \mathrm{MV}$ & $10 \mathrm{MV}$ & $6 \mathrm{MV}$ \\
\hline 1 & 196.25 & 183.94 & 77.8 & 77.80 & 66.8 & 66.20 & 42.46 & 41.87 & 76.4 & 80.00 & 55.3 & 55.9 \\
\hline 2 & 121.35 & 125.97 & 61.2 & 60.40 & 52 & 52.80 & 34.6 & 35.09 & 77.9 & 80.10 & 54.7 & 54.1 \\
\hline 3 & 97.37 & 101.65 & 78.1 & 78.10 & 73.8 & 73.80 & 46.23 & 47.08 & 79.2 & 81.60 & 58.9 & 58.9 \\
\hline 4 & 110.93 & 116.93 & 76 & 75.90 & 65.6 & 66.40 & 39.17 & 40.63 & 77.3 & 79.20 & 56.5 & 57.4 \\
\hline 5 & 160.61 & 170.94 & 77.6 & 77.80 & 71.9 & 71.90 & 42.71 & 44.26 & 82.5 & 86.50 & 60.7 & 62.2 \\
\hline 6 & 186.35 & 196.65 & 78.9 & 78.90 & 75.5 & 75.50 & 51.83 & 53.15 & 84 & 87.00 & 59.5 & 61.5 \\
\hline 7 & 305.76 & 316.54 & 78.2 & 78.50 & 76.9 & 76.90 & 72.57 & 72.70 & 91.8 & 94.80 & 74.9 & 75.8 \\
\hline 8 & 465.60 & 484.58 & 62.6 & 63.20 & 61.5 & 61.50 & 59.6 & 59.80 & 96.1 & 97.30 & 78.2 & 79.5 \\
\hline 9 & 106.78 & 111.90 & 60.4 & 60.40 & 57.7 & 57.70 & 32.63 & 33.69 & 76.7 & 80.40 & 50.8 & 50.8 \\
\hline 10 & 23.73 & 23.79 & 46 & 46.00 & 45.5 & 45.50 & 41.96 & 41.89 & 76.4 & 74.90 & 64.4 & 63.4 \\
\hline 11 & 111.81 & 113.54 & 53.3 & 53.60 & 53.1 & 53.10 & 52 & 51.80 & 96.7 & 97.50 & 86.6 & 86.7 \\
\hline 12 & 23.96 & 24.53 & 22.6 & 22.80 & 22.2 & 22.40 & 21.24 & 21.35 & 76.4 & 75.80 & 55.3 & 58.3 \\
\hline 13 & 31.40 & 31.96 & 22.6 & 22.40 & 22.4 & 22.30 & 21.73 & 21.70 & 68.9 & 68.90 & 46.2 & 47.1 \\
\hline 14 & 255.93 & 261.87 & 53.5 & 53.10 & 52.8 & 52.40 & 51.54 & 51.56 & 94.8 & 96.80 & 78.9 & 79.5 \\
\hline 15 & 72.14 & 74.35 & 37.9 & 37.90 & 37.2 & 37.00 & 33.27 & 33.36 & 73.7 & 75.20 & 54.7 & 55.3 \\
\hline 16 & 176.28 & 180.71 & 62.4 & 62.40 & 61.3 & 61.30 & 57.51 & 57.73 & 83 & 85.80 & 64.4 & 64.5 \\
\hline 17 & 261.52 & 269.52 & 63.7 & 64.30 & 62.4 & 62.60 & 54.88 & 54.54 & 79.8 & 82.00 & 61.9 & 62.2 \\
\hline 18 & 87.99 & 88.90 & 38.6 & 38.40 & 37.8 & 37.80 & 36.86 & 36.82 & 84.9 & 87.00 & 61.9 & 61.9 \\
\hline 19 & 587.80 & 603.83 & 55.8 & 56.40 & 54.1 & 54.30 & 52.37 & 52.48 & 100 & 100 & 90.6 & 91.8 \\
\hline Mean & 178.08 & 183.27 & 58.27 & 58.33 & 55.29 & 55.34 & 44.48 & 44.82 & 82.97 & 84.78 & 63.92 & 64.57 \\
\hline SD & 147.71 & 152.38 & 18.13 & 18.17 & 16.32 & 16.32 & 13.00 & 12.96 & 8.85 & 8.96 & 12.24 & 12.29 \\
\hline$P$ value & \multicolumn{2}{|c|}{0.004} & \multicolumn{2}{|c|}{0.476} & \multicolumn{2}{|c|}{0.536} & \multicolumn{2}{|c|}{0.03} & \multicolumn{2}{|c|}{0.0001} & \multicolumn{2}{|c|}{0.006} \\
\hline
\end{tabular}

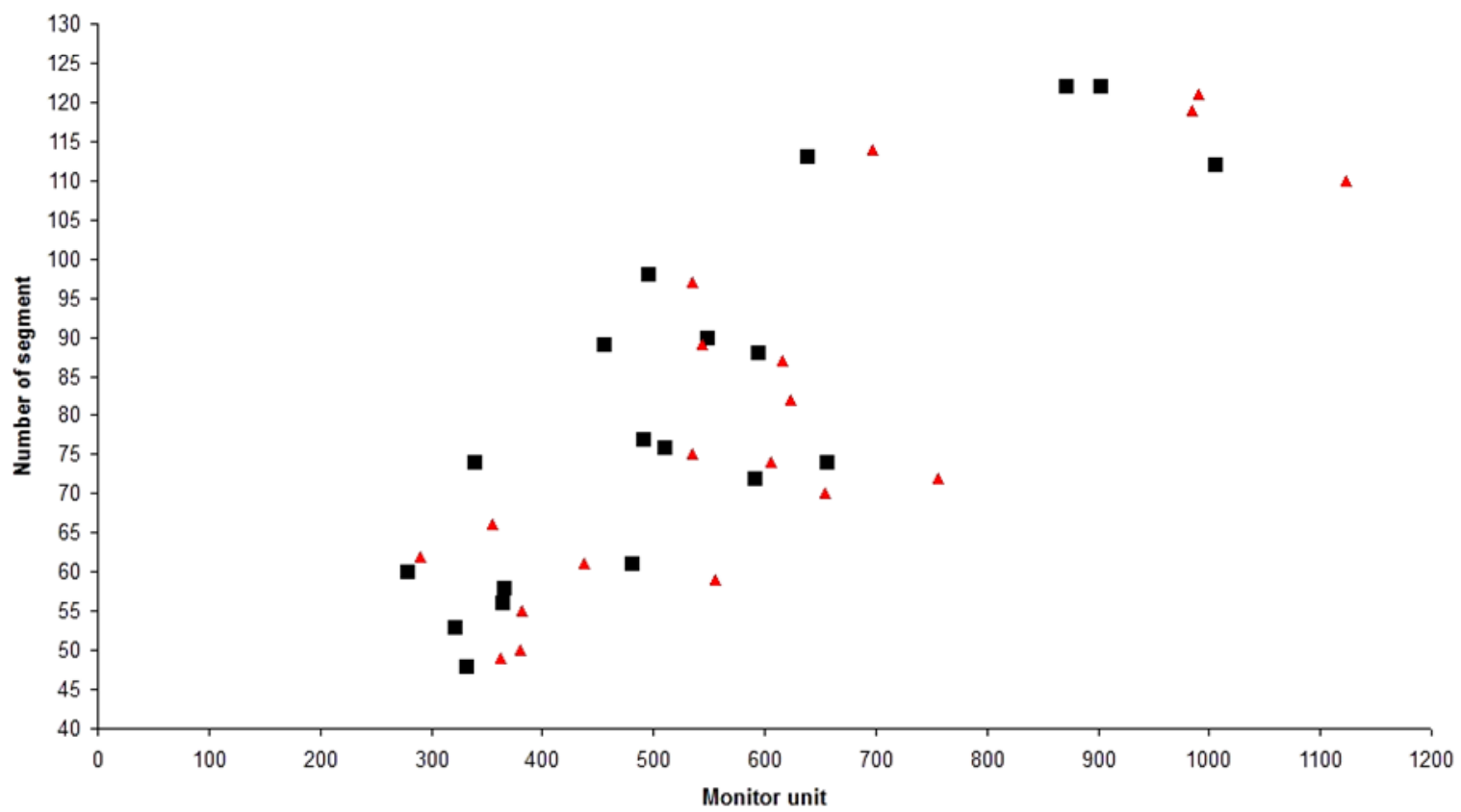

Figure 5. Case by case comparison of the delivering MU and number of segment between $6 \mathrm{MV}$ and $10 \mathrm{MV}$ plans. 
conduct photon and neutron measurements considering complication calculation, attempted to address 15-MV energy IMRT benefits outweighing risk.

Park JM et al. [21] suggested that mixing high- and low-energy photon beams in an IMRT plan for deepseated tumors can improve the overall plan quality. Sung $\mathrm{W}$ et al. [22] compared the effect of three photon energies (6-MV, 10-MV, and 15-MV) on IMRT plans to treat twenty prostate cancer patients, 10-MV plans showed better OAR sparing and less integral doses than the 6MV. In agreement with that work this study indicates that the use of $10 \mathrm{MV}$ photons was dosimetrically comparable with $6 \mathrm{MV}$ photons in terms of target coverage, homogeneity, conformity, and OAR savings. The dose to the normal tissue surrounding the target volume was found to be higher for the 6-MV than 10-MV beams, but it should be taken into consideration that for 6-MV there are no secondary neutrons, and radiation leakage is relatively low, also room shielding requirements are significantly less for 6-MV photons than for 10-MV photons.

\section{Conclusion}

In conclusion, the use of high-energy 10-MV photon achieves the same tumour control as the 6-MV photon with acceptable complication rate as well as better saving for normal tissue, while generating negligible neutron dose equivalent. It is recommended that the choice to treat at $10 \mathrm{MV}$ be taken as a risk vs. benefit as the clinical significance remains to be determined on case by case basis.

\section{REFERENCES}

[1] M. J. Zelefsky, Y. Yamada, Z. Fuks, et al., "Long-Term Results of Conformal Radiotherapy for Prostate Cancer: Impact of Dose Escalation on Biochemical Tumor Control and Distant Metastases-Free Survival Outcomes," International Journal of Radiation Oncology, Biology and Physics, Vol. 71, No. 4, 2008, pp. 1028-1033. http://dx.doi.org/10.1016/j.ijrobp.2007.11.066

[2] J. C. Chow, G. N. Grigorov, R. B. Barnett, "Study on Surface Dose Generated in Prostate Intensity-Modulated Radiation Therapy Treatment," Medical Dosimetry, Vol. 31, No. 4, 2006, pp. 249-258. http://dx.doi.org/10.1016/j.meddos.2005.07.002

[3] F. d'Errico, "Dosimetric Issues in Radiation Protection of Radiotherapy Patients," Mathematics \& Physical Sciences, Vol. 118, No. 2, 2006, pp. 205-212. http://dx.doi.org/10.1093/rpd/ncl034

[4] M. Westermark, J. Arndt, B. Nilsson and A. Brahme, "Comparative Dosimetry in Narrow High-Energy Photon Beams," Physics in Medicine and Biology, Vol. 45, No. 3, 2000, pp. 685-702. http://dx.doi.org/10.1088/0031-9155/45/3/308

[5] E. J. Hall, "Intensity-Modulated Radiation Therapy, Protons, and the Risk of Secondary Cancers," International
Journal of Radiation Oncology, Biology and Physics, Vol. 65, No. 1, 2000, pp. 1-7. http://dx.doi.org/10.1016/j.ijrobp.2006.01.027

[6] S. F. Kry, M. Salehpour, D. S. Followill, et al., "The Calculated Risk of Fatal Secondary Malignancies from Intensity-Modulated Radiation Therapy," International Journal of Radiation Oncology, Biology and Physics, Vol. 62, No. 4, 2005, pp. 1195-1203.

http://dx.doi.org/10.1016/j.ijrobp.2005.03.053

[7] A. Pirzkall, M. P. Carol, B. Pickett, P. Xia, M. Roach and L. J. Verhey, "The Effect of Beam Energy and Number of Fields on Photon-Based IMRT for Deep-Seated Targets," International Journal of Radiation Oncology, Biology and Physics, Vol. 53, No. 2, 2002, pp. 434-442. http://dx.doi.org/10.1016/S0360-3016(02)02750-5

[8] J. Stein, R. Mohan, X. H. Wang, et al., "Number and Orientations of Beams in Intensity-Modulated Radiation Treatments," Medical Physics, Vol. 24, No. 2, 1997, pp. 149160. http://dx.doi.org/10.1118/1.597923

[9] A. Van't Riet, A. C. Mak and M. A. Moerland, “A Conformation Number to Quantify the Degree of Conformality in Brachytherapy and External Beam Irradiation: Application to the Prostate," International Journal of Radiation Oncology, Biology and Physics, Vol. 37, No. 3, 1997, pp. 731-736. http://dx.doi.org/10.1016/S0360-3016(96)00601-3

[10] H. Aoyama, D. C. Westerley, T. R. Mackie, et al., "Integral Radiation Dose to Normal Structures with Conformal External Beam Radiation," International Journal of Radiation Oncology, Biology and Physics, Vol. 64, No. 3, 2006, pp. 962-967.

http://dx.doi.org/10.1016/j.ijrobp.2005.11.005

[11] J. S. Laughlin, R. Mohan and G. J. Kutcher, "Choice of Optimum Megavoltage for Accelerators for Photon Beam Treatment," International Journal of Radiation Oncology, Biology and Physics, Vol. 12, No. 9, 1986, pp. 1551-1557. http://dx.doi.org/10.1016/0360-3016(86)90277-4

[12] I. Madani, B. Vanderstraeten, S. Bral, et al., "Comparison of $6 \mathrm{MV}$ and $18 \mathrm{MV}$ Photons for IMRT Treatment of Lung Cancer," Radiotherapy and Oncology, Vol. 82, No. 1, 2007, pp. 63-69. http://dx.doi.org/10.1016/j.radonc.2006.11.016

[13] E. J. Hall and C. S. Wuu, "Radiation-Induced Second Cancer: The Impact of 3D-CRT and IMRT," International Journal of Radiation Oncology, Biology and Physics, Vol. 56, No. 1, 2003, pp. 83-88. http://dx.doi.org/10.1016/S0360-3016(03)00073-7

[14] S. Thangavelu, S. Jayakumar, K. N. Govindarajan, S. S. Supe, V. Nagarajan and M. Nagarajan, "Influence of Photon Energy on the Quality of Prostate Intensity Modulated Radiation Therapy Plans Based on Analysis of Physical Indices," Journal of Medical Physics, Vol. 36, No. 1, 2011, pp. 29-34.

http://dx.doi.org/10.4103/0971-6203.75469

[15] M. Sun and L. Ma, "Treatments of Exceptionally Large Prostate Cancer Patients with Low-Energy Intensity-Modulated Photons," Journal of Applied Clinical Medical Physics, Vol. 7, No. 4, 2006, pp. 43-49. 
[16] J. S. Welsh, T. R. Mackie and J. P. Limmer, "High-Energy Photons in IMRT: Uncertainties and Risks for Questionable Gain," Technology in Cancer Research and Treatment, Vol. 6, No. 2, 2007, pp. 147-149.

[17] S. F. D. Boer, Y. Kumek, W. Jaggernauth and M. B. Podgorsak, "The Effect of Beam Energy on the Quality of IMRT Plans for Prostate Conformal Radiotherapy," Technology in Cancer Research and Treatment, Vol. 6, No. 2, 2007, pp. 139-146.

[18] L. Wang, E. Yorke, G. Desobrya and C. S. Chui, "Dosimetric Advantage of Using $6 \mathrm{MV}$ over $15 \mathrm{MV}$ Photons in Conformal Therapy of Lung Cancer: Monte Carlo Studies in Patient Geometries," Journal of Applied Clinical Medical Physics, Vol. 3, No. 1, pp. 51-59. http://dx.doi.org/10.1120/1.1432862

[19] G. Solaiappan, G. Singaravelu, A. Prakasarao, B. Rabbani and S. S. Supe, "Influence of Photon Beam Energy on IMRT Plan Quality for Radiotherapy of Prostate Cancer," Reports of Practical Oncology and Radiotherapy, Vol. 14,
No. 1, 2009, pp. 18-31.

[20] M. Hussein, S. Aldridge, T. Guerrero Urbano and A. Nisbet, "The Effect of 6 and 15 MV on Intensity-Modulated Radiation Therapy Prostate Cancer Treatment: Plan Evaluation, Tumour Control Probability and Normal Tissue Complication Probability Analysis, and the Theoretical Risk of Secondary Induced Malignancies," British Journal of Radiology, Vol. 85, 2012, pp. 423-432. http://dx.doi.org/10.1259/bjr/24514638

[21] J. M. Park, C. H. Choi, S. W. Ha and S. J. Ye, "The Dosimetric Effect of Mixed-Energy IMRT Plans for Prostate Cancer," Journal of Applied Clinical Medical Physics, Vol. 12, No. 4, 2011, p. 3563.

[22] W. Sung, J. M. Park, C. H. Choi, S. W. Ha and S. J. Ye, "The Effect of Photon Energy on Intensity-Modulated Radiation Therapy (IMRT) Plans for Prostate Cancer," Journal of Radiation Oncology, Vol. 30, No. 1, 2012, pp. $27-$ 35. http://dx.doi.org/10.3857/roj.2012.30.1.27 